This is the accepted version of the article "Hole-selective front contact stack enabling 24.1\%-efficient silicon heterojunction solar cells 1 from M. Boccard et al., DOI: 10.1109/JPHOTOV.2020.3028262

(C) (C) 2019 IEEE. Personal use of this material is permitted. Permission from IEEE must be obtained for all other uses, in any current or future media, including reprinting/republishing this material for advertising or promotional purposes, creating new collective works, for resale or redistribution to servers or lists, or reuse of any copyrighted component of this work in other works.

Publisher version available at https://ieeexplore.ieee.org/abstract/document/9223729

\title{
Hole-selective front contact stack enabling $24.1 \%$-efficient silicon heterojunction solar cells
}

\author{
Mathieu Boccard, Luca Antognini, Vincent Paratte, Jan Haschke, Minh Truong, Jean Cattin, Julie \\ Dréon, Wenjie Lin, Laurie-Lou Senaud, Bertrand Paviet-Salomon, Sylvain Nicolay, Matthieu \\ Despeisse, Christophe Ballif
}

\begin{abstract}
The window-layer stack limits the efficiency of both-side-contacted silicon heterojunction solar cells. We discuss here the combination of several modifications to this stack to improve its optoelectronic performance. These include the introduction of a nanocrystalline silicon-oxide p-type layer in lieu of the amorphous silicon p-type layer, replacing indium tin oxide with a zirconium-doped indium oxide for the front transparent electrode, capping this layer with a silicon-oxide film, and applying a post-fabrication electrical biasing treatment. The influence of each of these alterations is discussed, as well as their interactions. Combining all of them finally enables the fabrication of a highly transparent and electrically well-performing windowlayer stack, leading to a screen-printed silicon heterojunction solar cell with $\mathbf{2 4 . 1 \%}$ efficiency. Paths towards industrialization and for further improvements are finally discussed.
\end{abstract}

Index Terms - anti-reflection coating, carrier-selective contact, heterojunction, nanocrystalline silicon, p-layer, passivating contact, silicon, silicon oxide, transparent conductive oxide.

\section{INTRODUCTION}

$\mathrm{C}$ RYSTALLINE silicon is the main photovoltaic absorber material since many decades, and this domination is set to

Manuscript received August 14, 2020. This project has received funding from the European Union's Horizon 2020 research and innovation program under Grant Agreement No. 727523 (NextBase) and 745601 (AMPERE), as well as Swiss national science foundation under Ambizione Energy grant ICONS (PZENP2_173627).

M. Boccard, L. Antognini, V. Paratte, M. Truong, J. Cattin, J. Dréon, W. Lin, C. Ballif are with the École Polytechnique Fédérale de Lausanne (EPFL), Institute of Microengineering (IMT), Photovoltaics and Thin Film Electronics Laboratory, Rue de la Maladière 71b, CH-2002 Neuchâtel, Switzerland (corresponding author: +41 21695 4558; fax: +41 21695 4201; e-mail: mathieu.boccard@epfl.ch).

J. Haschke was with École Polytechnique Fédérale de Lausanne (EPFL), Institute of Microengineering (IMT), Photovoltaics and Thin Film Electronics Laboratory, Rue de la Maladière 71b, CH-2002 Neuchâtel, Switzerland. He is now with REC Solar Pte. Ltd., 20 Tuas South Ave. 14, Singapore 637312, Singapore.

L.-L. Senaud, B. Paviet-Salomon, S. Nicolay and M. Despeisse are with the Centre Suisse d'Electronique et de Microtechnique SA (CSEM), Rue Jaquet-Droz 1, 2002 Neuchâtel, Switzerland. last for a few more years considering the current evolution of the market [1]. A sunlight-to-electricity conversion efficiency of $25 \%$ was demonstrated already at the turn of the century with a finely tuned homojunction architecture [2]. This value was surpassed multiple times in recent years through the advantageous use of full-area passivating contacts [3]. Amongst them, the silicon heterojunction (SHJ) architecture comprising intrinsic amorphous silicon ((i)a-Si:H) layers for passivation dominates the efficiency charts with all-back contacted devices reaching up to $26.7 \%$ efficiency [4]. This is $0.6 \%$ higher than the best device using a thin silicon oxide passivating layer combined with poly-silicon contacts [5]. However, efficiency in both-side contacted heterojunction devices hovers at $25.1 \%$ [6], [7], whereas devices using a homojunction at the front side (and a passivating contact on the rear side) recently reached up to $26.0 \%$ efficiency [8]. This difference is principally due to a lower short-circuit current density $\left(\mathrm{J}_{\mathrm{SC}}\right)$ for the $\mathrm{SHJ}$ cell, notably due to parasitic absorption of short-wavelength light in the window-layer stack (i.e. layers deposited on the light-incoming side of the wafer) when employing a full-area passivating-contact design [9]. A highest efficiency of $25.1 \%$ was interestingly obtained with either a hole-selective [6] or electron-selective [7] contact placed on the light-incoming side.

There are several opto-electrical trade-offs at stake in this window-layer stack: it should be highly transparent and minimize reflection over the spectrum of absorption of $\mathrm{Si}$, yet ensure excellent surface passivation and minimal-resistance charge collection to the metallic grid. (Achieving these two last properties naturally results in near-perfect charge selectivity [10].) These trade-offs typically call for opposite properties. For example, surface passivation requires the use of an (i)a-Si:H layer of at least a few nanometers, which is detrimental both in terms of electrical resistance and parasitic absorption. Then, the carrier density in the transparent 
This is the accepted version of the article "Hole-selective front contact stack enabling $24.1 \%$-efficient silicon heterojunction solar cells2 from M. Boccard et al., DOI: 10.1109/JPHOTOV.2020.3028262

(C) (C) 2019 IEEE. Personal use of this material is permitted. Permission from IEEE must be obtained for all other uses, in any current or future media, including reprinting/republishing this material for advertising or promotional purposes, creating new collective works, for resale or redistribution to servers or lists, or reuse of any copyrighted component of this work in other works.

Publisher version available at https://ieeexplore.ieee.org/abstract/document/9223729

conductive oxide (TCO) should be high to minimize electrical resistance, yet low to minimize parasitic infrared-light absorption. The same goes for the thickness of the doped a$\mathrm{Si}: \mathrm{H}$ layer [9]. In all cases, it is possible to tune specific properties of the involved material to relax the trade-off. This can be the microstructure factor for the (i)a-Si:H layer [11][13], the electron mobility for the TCO [14]-[16], or the composition of the thin-film-silicon doped layer [17]-[19].

Using such approach systematically, we applied three alterations to our standard window-layer stack, which enabled to reach a certified solar cell efficiency over $24 \%$ starting from a 23.2\%-efficient device [20]. These are sketched in Figure 1, and consist of 1) replacing the a-Si:H p-type layer by a nanocrystalline-silicon-oxide $\left(\mathrm{nc}-\mathrm{SiO}_{\mathrm{x}}: \mathrm{H}\right)$ layer, 2) replacing the indium tin oxide (ITO) with zirconium-doped indium oxide (IZrO) for the front TCO, and 3) applying a hydrogenating silicon-oxide $\left(\mathrm{SiO}_{\mathrm{x}}: \mathrm{H}\right)$ second anti-reflection coating layer. A final post-fabrication step is to subject the device to an electrical-bias post-treatment. We focus on front-junction configuration which is less documented than the rear-junction one (in particular when involving nc-SiO $: \mathrm{H}^{\mathrm{n}}$ layers [21], [22]), to investigate whether high efficiencies can be reached with such films.

Alloying nc-Si:H with oxygen was established as an efficient strategy to obtain a more performant front contact layer in thin-film silicon devices [22]-[26]. A similar approach was then applied to SHJ solar cells, with a clear optical benefit but electrical losses [27]. Concerning the front TCO film, the use of IZrO was shown to enable highly efficient SHJ solar cells [28]. This stems from the high electron mobility reached in this material, similarly to other In-based TCOs [16], [29][31], which enables to achieve sufficient conductivity with a free-carrier density below $4 \times 10^{20} \mathrm{~cm}^{-3}$. This ensures simultaneously low resistive losses and low parasitic freecarrier absorption for the solar cell [32]. Another approach to minimize resistive and optical losses in the front TCO layer is to coat it with a $\mathrm{SiO}_{\mathrm{x}}: \mathrm{H}$ film: such additional coating was shown to both improve the transmittance of light to the silicon wafer and reduce the sheet resistance of the TCO [33], [34]. A similar approach can be economically relevant for highvolume manufacturing [35], and increase the reliability of SHJ solar cells when combined to a tungsten-doped indium-oxide film [13]. The last building block used in the reported results is the application of a forward electrical bias to the finished solar cell. This step was shown to increase the performance of SHJ devices-similarly to the exposure to illumination at open-circuit conditions - due to a passivation improvement stemming from the recombination of charges injected in the silicon wafer [36]. This effect is thus expected to occur in the first few weeks of module operation [37].

All the four elements used in our approach have therefore already been individually implemented but not yet combined in a unique high-efficiency device. Such combination is not straightforward as all layers involved in a SHJ contact stack interact, either by altering the growth of the subsequent layer or by modifying the physical or chemical properties of the underlying ones: This typically prevents the direct growth of doped nc-Si $\left(\mathrm{O}_{\mathrm{x}}\right): \mathrm{H}$ films directly on the passivating (i)a-Si:H layer, requiring the use of intermediate processes to promote nucleation [38], [39]. Similarly, the growth of TCO films is influenced by the nature of the doped silicon layer it grows on, with lower-conductivity films typically obtained on nc-Si:H films than on a-Si:H films for identical growth conditions as exemplified in Figure 1c [20], [40]. Then, although the addition of an $\mathrm{SiO}_{\mathrm{x}}$ (or $\mathrm{SiN}_{\mathrm{x}}$ ) capping layer has been demonstrated as beneficial for multiple TCOs (ITO [33], tungsten-doped indium oxide [13], aluminum-doped zinc oxide [41]), this is still unexplored for $\mathrm{IZrO}$, even less so for an $\mathrm{IZrO}$ layer grown on a $\mathrm{nc}-\mathrm{SiO}_{\mathrm{x}}: \mathrm{H}$ film. Lastly, little literature is available on the influence of the device architecture on the effect of a forward bias treatment. Notably, the beneficial effects on the silicon passivation of applying a light soaking treatment (supposedly identical to a forward bias) rely on the presence of the doped layers: samples passivated with a simple (i)a-Si:H film were shown to degrade upon such treatment [36], [42]. In particular, the p-type layer thickness was shown critical for front-junction solar cells, with forward bias yielding improvements even in conditions for which the light soaking led to degradation [43]; the effect of such treatment on devices using $(\mathrm{p}) \mathrm{nc}-\mathrm{SiO}_{\mathrm{x}}: \mathrm{H}$ layers has so far not yet been experimentally tested.

\section{EXPERIMENTAL DETAILS}

Figure 1 shows the schematics of the devices discussed here. These are front-junction silicon heterojunction solar cells processed as follows on 100-mm-diameter, n-type, float-zone silicon wafers with a resistivity of $1.7-2.3 \Omega \cdot \mathrm{cm}$, and a thickness of $195 \mu \mathrm{m}$. After the formation of random pyramidal texturing and cleaning using standard chemical baths, the wafers were subjected to a one-minute dip in hydrofluoric acid (HF) followed by loading in a plasma-enhanced-chemicalvapor-deposition (PECVD) reactor to deposit the thin-film silicon layers. A 9-nm-thick (as measured on the flat witness glass) (i)a-Si:H film was then grown on the rear side, followed 
This is the accepted version of the article "Hole-selective front contact stack enabling 24.1\%-efficient silicon heterojunction solar cells3 from M. Boccard et al., DOI: 10.1109/JPHOTOV.2020.3028262

(C) (C) 2019 IEEE. Personal use of this material is permitted. Permission from IEEE must be obtained for all other uses, in any current or future media, including reprinting/republishing this material for advertising or promotional purposes, creating new collective works, for resale or redistribution to servers or lists, or reuse of any copyrighted component of this work in other works.

Publisher version available at https://ieeexplore.ieee.org/abstract/document/9223729

by a phosphorus-doped n-type film with a thickness of $30 \mathrm{~nm}$ on glass. After flipping the wafer in air, the same (i)a-Si:H film was grown on the other side, followed by the p-type layer. Reference samples were prepared with a (p)a-Si:H film, yet most devices discussed here include a nanocrystalline-silicon (nc-Si:H) or nanocrystalline-silicon-oxide (nc-SiO $: \mathrm{H}$ ) film. In the case of $n c-S i: H$ or $n c-S i O_{x}: H$ films, an oxidizing plasma treatment was performed on top of the (i)a-Si:H layer, enabling incubation-free nucleation of the nanocrystallites [39], and the reactor temperature was set to $175^{\circ} \mathrm{C}$ (in lieu of the $200{ }^{\circ} \mathrm{C}$ used for all other PECVD layers) as this was shown to promote higher-crystallinity layers [44]. A transparent conductive oxide (TCO) was then deposited by reactive sputtering on the front-side using a shadow mask to define five $2 \times 2 \mathrm{~cm}^{2}$ cells per wafer. This front TCO consisted of either ITO deposited using $1000 \mathrm{~W}$ direct-current (DC) excitation power or IZrO deposited using $600 \mathrm{~W}$ radio-frequency (RF) excitation power, from $378 \times 120 \mathrm{~mm}^{2}$ targets. The scanning speed was adjusted to reach a thickness (on the textured wafer) of either $75 \mathrm{~nm}$ or $50 \mathrm{~nm}$, to achieve optimal conditions for single-layer or double-layer anti-reflection coating [41]. On the rear side, a 150-nm-thick ITO film was deposited prior to the silver layer (full area in both cases) to mitigate parasitic absorption [45]. A silver front grid (external busbars, 1.85-mm finger pitch, $40-\mu \mathrm{m}$ finger width, total shading estimated to $2.3 \%$ ) was screen-printed on the front side, which was cured at $210{ }^{\circ} \mathrm{C}$ for 30 minutes in a belt furnace. This annealing step also cures sputtering-induced damage and improves the conductivity of the TCO film [46]. When applied, a 100-nmthick $\mathrm{SiO}_{\mathrm{x}}$ film with a refractive index of 1.5 at $600 \mathrm{~nm}$ was deposited on top of the TCO film by PECVD at $180{ }^{\circ} \mathrm{C}$. Finally, some devices were subjected to a forward electric bias with a current density of $40 \mathrm{~mA} / \mathrm{cm}^{2}$ for two weeks in the dark, mimicking beneficial light soaking as described in [43].

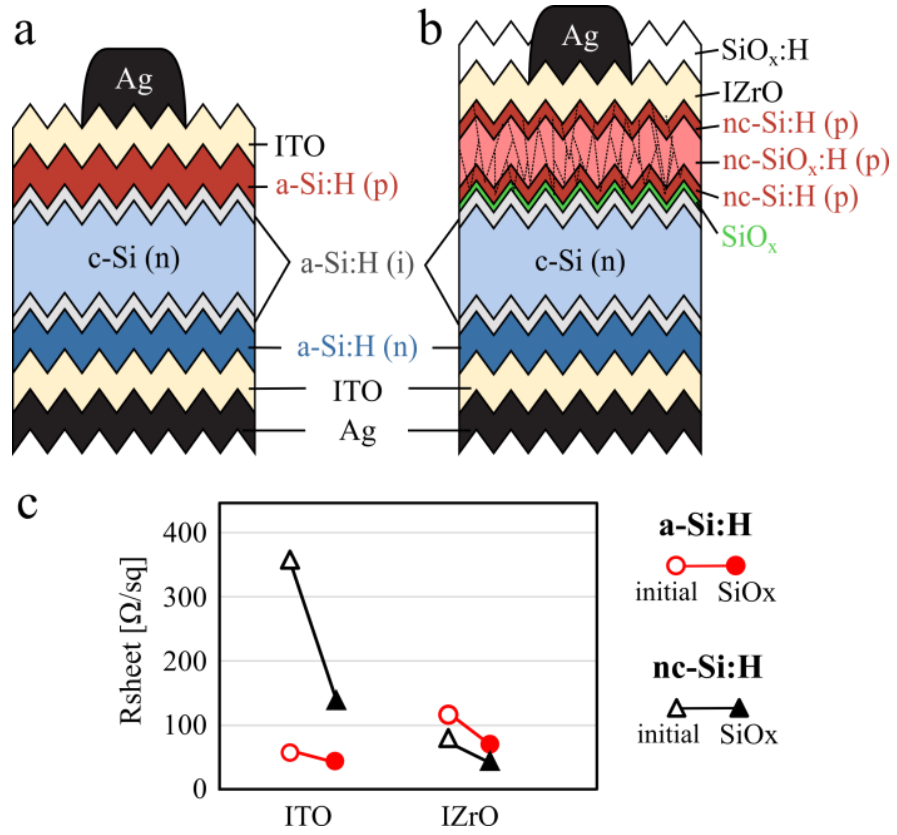

Fig. 1. a,b) Sketch of the standard device (a) and of the improved device (b). c) Sheet resistance of the front TCO measured on a pad directly on the wafer before or after deposition of a SiOx capping layer for a-Si:H or nc-Si:H (p) layers and ITO or IZrO as transparent electrode.

\section{RESULTS AND DISCUSSION}

Figure 2 shows current-voltage (IV) metrics for eight different solar cell structures, consisting of a variation of the hole contact (a-Si:H or nc-Si:H), the TCO layer (ITO or IZrO) and the capping layer (nothing or $\mathrm{SiO}_{\mathrm{x}}$ ). The addition of the $\mathrm{SiO}_{\mathrm{x}}$ capping layer brings a systematic improvement to all devices, irrespective of the nature of their p-type and TCO layers. In the case of the $\mathrm{IZrO}$ film, the slight gain originates only from $\mathrm{J}_{\mathrm{SC}}$ increase due to the lower reflection, without any significant change of open-circuit voltage $\left(\mathrm{V}_{\mathrm{OC}}\right)$ or fill factor (FF). Conversely, both $\mathrm{J}_{\mathrm{SC}}$ and $\mathrm{FF}$ are improved upon $\mathrm{SiO}_{\mathrm{x}}$ deposition for the cells using an ITO contact. This FF gain originates from series-resistance reduction, since this layer was relatively resistive prior to the $\mathrm{SiO}_{x}$ deposition as it was grown under conditions optimized for the post-SiO ${ }_{x}$ state [33]. The ITO film was also slightly thinner than the $\mathrm{IZrO}$ one, thus inducing more reflection prior to $\mathrm{SiO}_{\mathrm{x}}$ deposition [41]. 
This is the accepted version of the article "Hole-selective front contact stack enabling 24.1\%-efficient silicon heterojunction solar cells4 from M. Boccard et al., DOI: 10.1109/JPHOTOV.2020.3028262

(C) (C) 2019 IEEE. Personal use of this material is permitted. Permission from IEEE must be obtained for all other uses, in any current or future media, including reprinting/republishing this material for advertising or promotional purposes, creating new collective works, for resale or redistribution to servers or lists, or reuse of any copyrighted component of this work in other works.

Publisher version available at https://ieeexplore.ieee.org/abstract/document/9223729

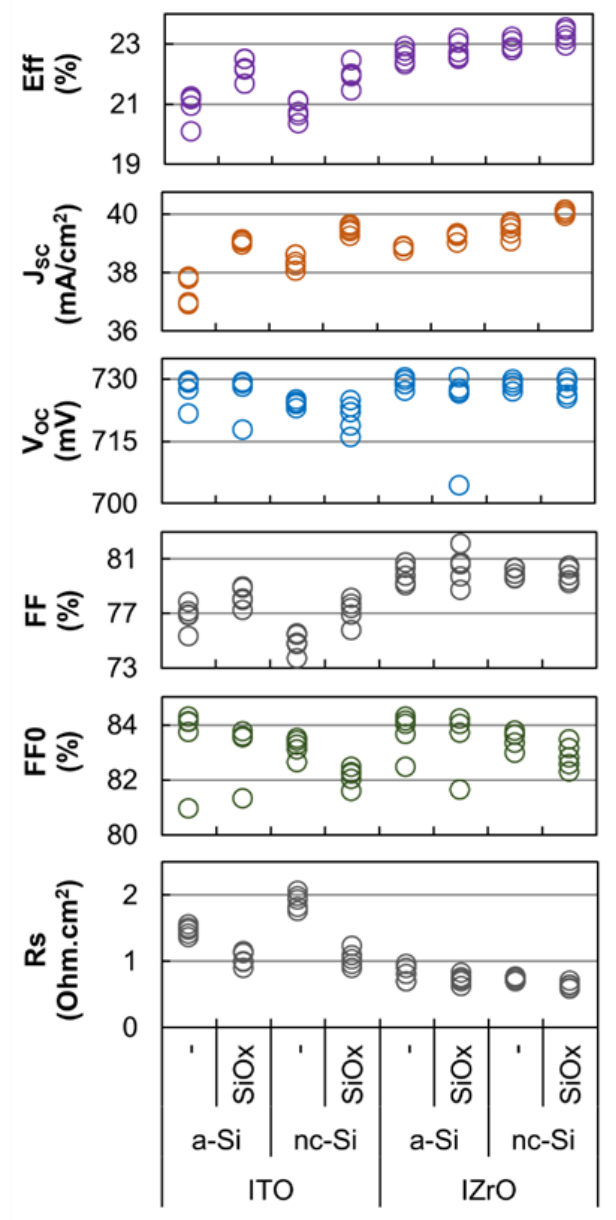

Fig. 2. Solar cell characteristics for devices incorporating either an a-Si:H or a nc-Si:H (p) layer, and an ITO or IZrO front TCO, prior to or after the deposition of the $\mathrm{SiO}_{\mathrm{x}}: \mathrm{H}$ capping layer.

Then, comparing the performance of solar-cells using either ITO or IZrO, similar $\mathrm{V}_{\mathrm{OC}}$ are obtained but the use of $\mathrm{IZrO}$ enables slightly higher $\mathrm{J}_{\mathrm{SC}}$ and largely improved FF. The latter partly originates from slightly better passivations (higher $\mathrm{FF}_{0}$ ) presumably originating from the $20 \%$ lower power used for IZrO sputtering compared to ITO, yet most of the gain comes from reduced series resistance. This stems from improved charge transport on the hole-collecting side due to the use of $\mathrm{IZrO}$ thanks to the lower sheet resistance of the $\mathrm{IZrO}$ than ITO, even after the $\mathrm{SiO}_{\mathrm{x}}$ deposition. Note that although a similar sheet resistance is reachable by decreasing the oxygen content during ITO sputtering in our tool, this comes at the expense of lower transparency, detrimental to Jsc as was previously reported [28]. The higher mobility of IZrO ( 60 $\mathrm{cm}^{2} / \mathrm{Vs}$ in this experiment compared to $\sim 30 \mathrm{~cm}^{2} / \mathrm{Vs}$ for ITO) enables to reach simultaneously high transparency and conductivity [32]. Finally, the use of the (p)nc-Si:H instead of
(p)a-Si:H enables higher $\mathrm{J}_{\mathrm{SC}}$ without affecting the Voc and FF, leading to the highest overall efficiency for the combination of (p)nc-Si:H with $\mathrm{IZrO}$ and $\mathrm{SiO}_{x}$ capping layer. A lower Voc is observed when combining (p)nc-Si:H and ITO, which is attributed to poorer passivation for this particular wafer, presumably unrelatedly to the contact choice.

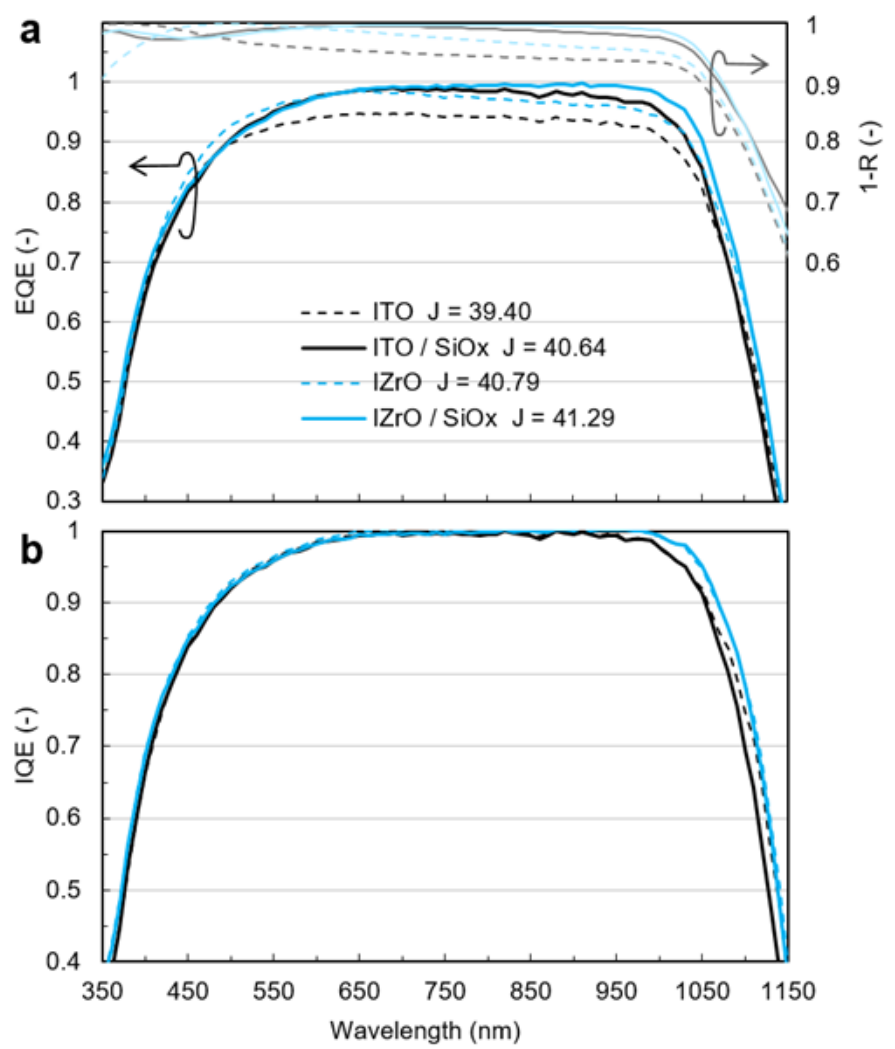

Fig. 3. a) External quantum efficiency (EQE) and one minus reflectance (1-R) for solar cells employing ITO or IZrO front electrodes, uncapped or capped with SiOx. b) Internal quantum efficiency (IQE) of the same samples.

Figure 3a shows external quantum efficiency (EQE) and total absorptance calculated as one minus the reflectance (1-R) both probed on a non-metallized area, for samples using the (p)nc-Si:H layer. ITO and IZrO are compared, and data is shown for both prior to and after the SiOx deposition. Reflection is greatly reduced when adding the SiOx layer in both cases. A larger gain is seen for the ITO film which was slightly thinner, yet after $\mathrm{SiOx}$ deposition the IZrO layer yields the lowest total reflectance overall after SiOx deposition thanks to lightly better performance in the near-infrared range. This is ascribed to the higher refractive index $(n)$ in the infrared compared to ITO, due to the lower influence of free carriers on $n$. Figure $3 \mathrm{~b}$ shows internal quantum efficiency (IQE) for all four conditions. The use of IZrO enables a slight gain in the UV part of the spectrum, and a more substantial one in the infra-red part. The former originates from the 
This is the accepted version of the article "Hole-selective front contact stack enabling 24.1\%-efficient silicon heterojunction solar cells5 from M. Boccard et al., DOI: 10.1109/JPHOTOV.2020.3028262

(C) (C) 2019 IEEE. Personal use of this material is permitted. Permission from IEEE must be obtained for all other uses, in any current or future media, including reprinting/republishing this material for advertising or promotional purposes, creating new collective works, for resale or redistribution to servers or lists, or reuse of any copyrighted component of this work in other works.

Publisher version available at https://ieeexplore.ieee.org/abstract/document/9223729

slightly wider bandgap, whereas the latter is due to lower freecarrier absorption. In this spectral range, the addition of $\mathrm{SiO}_{\mathrm{x}}$ on ITO leads to a decrease of IQE accompanying the sheetresistance drop shown in Figure 1c. Conversely, IQE of the IZrO sample remains remarkably high in spite of the low sheet resistance achieved, thanks to the high electron mobility in this material. IQE of the sample using an SiOx-capped $\mathrm{IZrO}$ electrode stays thus above $99 \%$ in the $640-1000 \mathrm{~nm}$ range.

Figure 4 describes the effect on devices of introducing $\mathrm{CO}_{2}$ in the gas mix during the (p)nc-Si:H layer growth to push further its transparency by alloying it with oxygen. To investigate an eventual detrimental alteration of the (p)nc$\mathrm{Si}$ :H-layer nucleation or of its interface with the TCO film, either the first or the last minute of the 5.5-minute deposition was performed without $\mathrm{CO}_{2}$ as also performed in reference [47]. A reference device without $\mathrm{CO}_{2}$ all along the growth was also produced, as well as a sample without $\mathrm{CO}_{2}$ during both the first and last minute. As shown in Figure 4a, similar efficiency can be obtained with a (p)nc-SiO $\mathrm{x}: \mathrm{H}$ layer as with a (p)nc-Si:H layer providing that both interfaces are kept $\mathrm{CO}_{2}$ free. $\mathrm{V}_{\mathrm{OC}}$ is slightly improved when incorporating $\mathrm{CO}_{2}$ in any part of the film, possibly owing to the increase of the layer resistance or to its wider bandgap [10], [21], [25], [48]. A $\mathrm{J}_{\mathrm{SC}}$ increase is obtained when adding $\mathrm{CO}_{2}$, even when only in the bulk part of the layer, at the cost of a FF drop discussed below.

Figure $4 \mathrm{~b}$ pictures the changes in thermal activation of charge transport when using the different versions of (p)nc$\mathrm{SiO}_{\mathrm{x}}: \mathrm{H}$ layers discussed here. Upon heating an ideal solar cell, $\mathrm{FF}$ is decreasing, due to the temperature-induced $\mathrm{V}_{\mathrm{OC}}$ decrease; For silicon heterojunction solar cells, this trend is modified at low temperatures, and FF actually decreases upon cooling below a certain temperature due to thermally-activated transport for hole collection [49]. As can be seen in Figure 4b, this phenomenon is present in all studied devices, and a FF maximum is indeed observed for all device incorporating $\mathrm{CO}_{2}$. For the no- $\mathrm{CO}_{2}$ reference, it occurs at a slightly lower temperature than $15{ }^{\circ} \mathrm{C}$, indicating that minimal series resistance is originating from the TCO-Si contact resistance.

Introducing $\mathrm{CO}_{2}$ in any part of the (p)nc-Si:H layer reduces the maximum FF value and pushes it to higher temperatures. For devices incorporating (p)nc-SiO ${ }_{x}: \mathrm{H}$ films, the temperature at which $\mathrm{FF}$ peaks is highest for the layer with $\mathrm{CO}_{2}$ at the (p)nc-SiO $\mathrm{Si}_{\mathrm{x}} \mathrm{H} / \mathrm{TCO}$ interface, and minimal for the layer without $\mathrm{CO}_{2}$ at both interfaces. For that specific device, FF is only moderately deviating from the theoretical linear trend for $25^{\circ} \mathrm{C}$ (which corresponds to standard test conditions, STC).

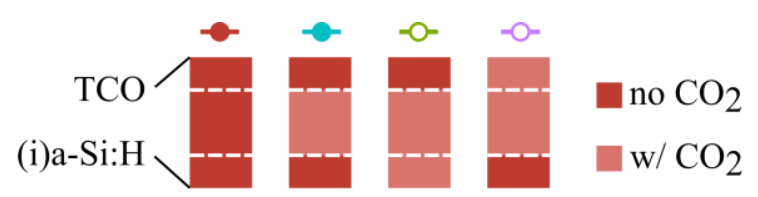

a
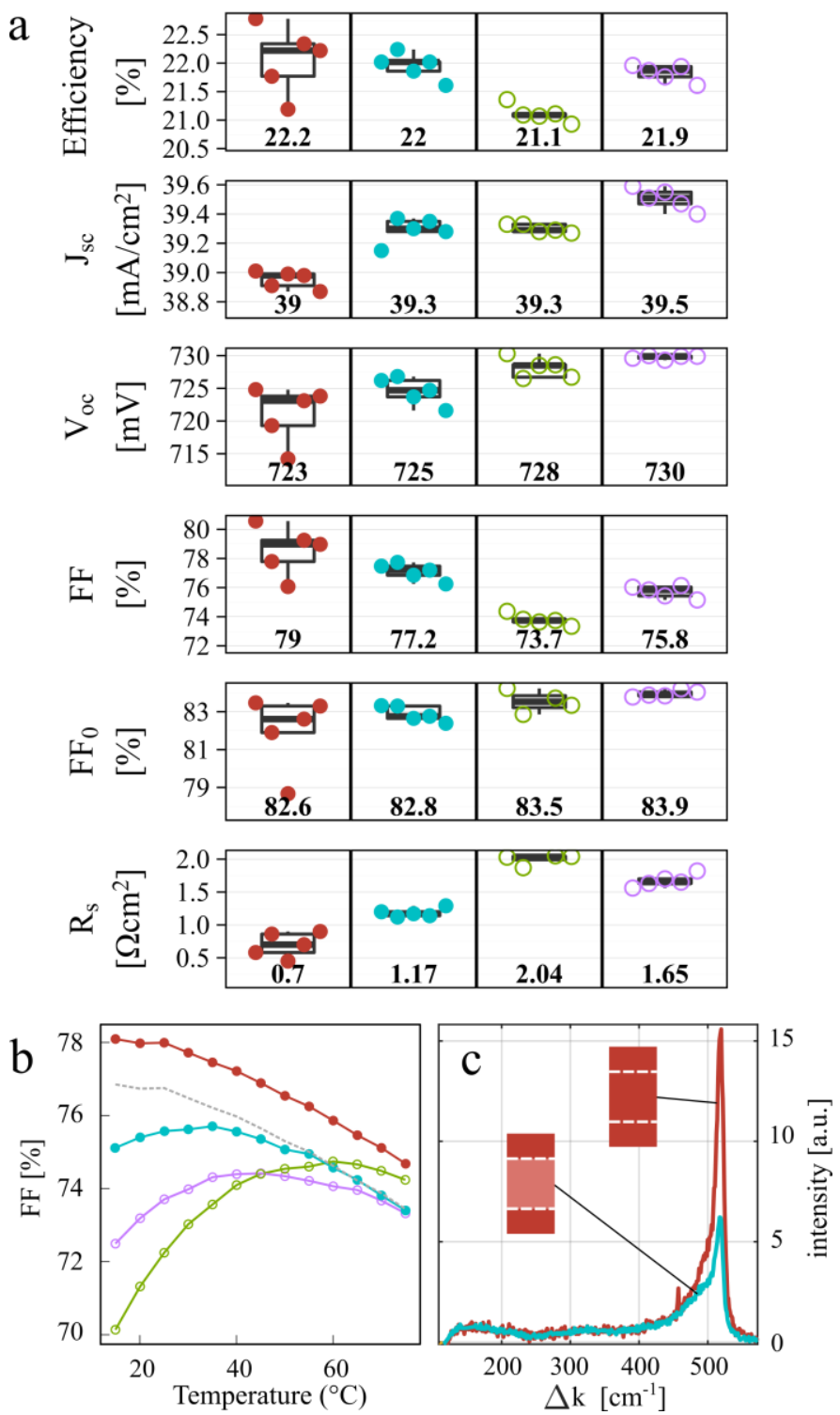

Fig. 4. a) Solar cell characteristics for devices incorporating a (p)nc-Si:H layer or a three-layer stack composed of either (p)nc-Si:H or (p)nc-SiO $\mathrm{x}: \mathrm{H}$ for the bottom, middle and top parts as sketched on top of the figure. b) temperature-dependent FF for the same devices as described in a). The dashed gray line corresponds to the no-CO2 curve shifted down by $\sim 1.3 \%$. c) Raman crystallinity of the non-oxyde (p)nc-Si:H layer and of the (p)nc-SiOx:H stack with both the bottom and top sub-layers grown without $\mathrm{CO}_{2}$.

Besides, a significant part of the $2.8 \%$ FF drop observed at STC compared to the device using a (p)nc-Si:H is also present at $70{ }^{\circ} \mathrm{C}$ in the linear part of the curve as evidenced by the dashed gray line corresponding to the FF of the (p)nc-Si:H 
This is the accepted version of the article "Hole-selective front contact stack enabling $24.1 \%$-efficient silicon heterojunction solar cells 6 from M. Boccard et al., DOI: 10.1109/JPHOTOV.2020.3028262

(C) (C) 2019 IEEE. Personal use of this material is permitted. Permission from IEEE must be obtained for all other uses, in any current or future media, including reprinting/republishing this material for advertising or promotional purposes, creating new collective works, for resale or redistribution to servers or lists, or reuse of any copyrighted component of this work in other works.

Publisher version available at https://ieeexplore.ieee.org/abstract/document/9223729

device shifted down by $\sim 1.3 \%$. This indicates that part of the $2.8 \%$ FF drop is actually not caused by a thermally activated barrier but by a temperature-independent contribution (e.g. grid resistance or TCO sheet resistance variability), and might therefore not be linked to the use of a (p)nc-SiO $\mathrm{x}: \mathrm{H}$ film as will be confirmed later.

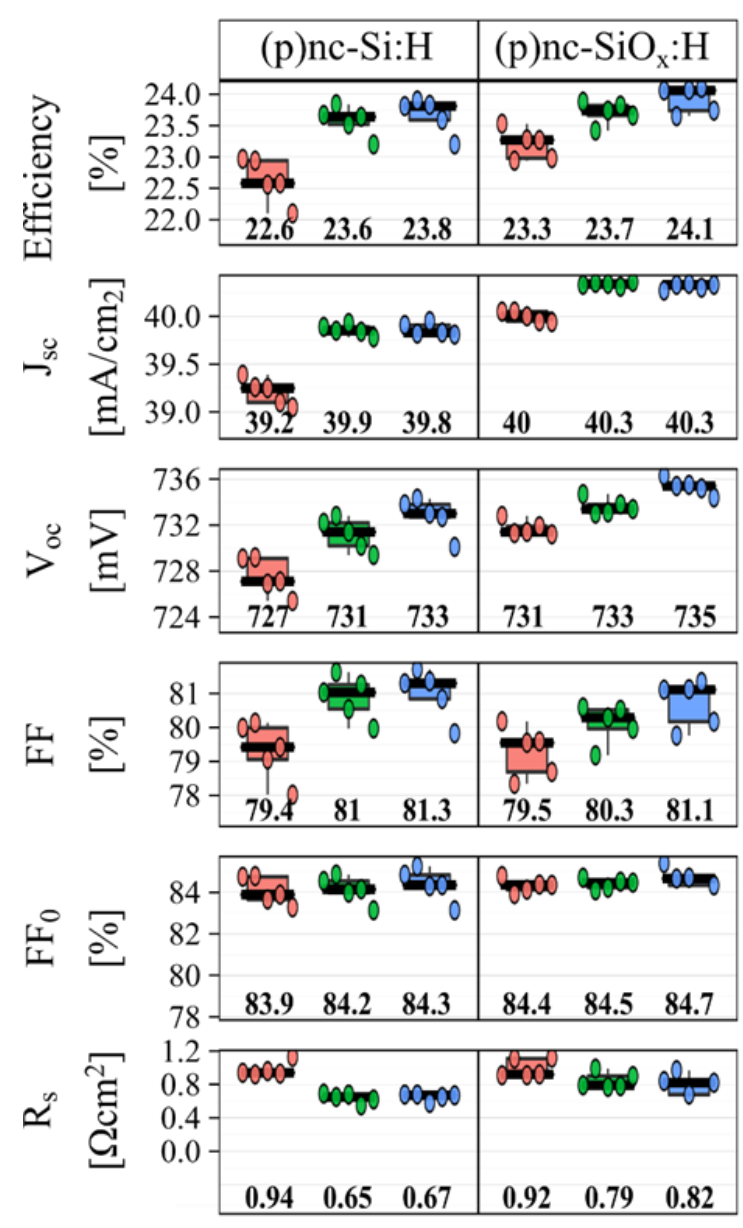

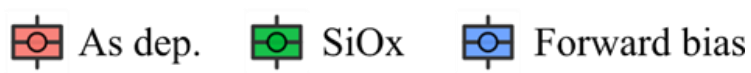

Fig. 5. Solar cell characteristics for devices incorporating a (p)nc-Si:H or three-layer stack with (p)nc-SiO $\mathrm{x}: \mathrm{H}$ in between two non-oxyde layers. The asdeposited state is reported, as well as the ones after the $\mathrm{SiO}_{\mathrm{x}}$ coating on top of the $\mathrm{IrO}$ and after the forward electrical bias.

Figure 4c shows Raman spectra of the nc-SiO $\mathrm{x}: \mathrm{H}$ with both interfaces grown without $\mathrm{CO}_{2}$, acquired with a 325-nm laser on a complete solar cell device in an area non-coated by the TCO. The strong signal between $510 \mathrm{~cm}^{-1}$ and $520 \mathrm{~cm}^{-1}$ shifts confirms the nanocrystalline nature of this film. The relative magnitude of this peak compared to the one from the amorphous phase at $480 \mathrm{~cm}^{-1}$ is lower than for the $\mathrm{nc}-\mathrm{Si}: \mathrm{H}$ film (also shown in Figure 4c). Note that such lower crystallinity is common for oxide alloys and is not necessarily detrimental to solar cell performance [24].

Figure 5 eventually shows the influence of applying a forward-bias treatment on solar cells incorporating all aforementioned developments. Devices with a (p)nc-Si:H and a (p)nc-SiO $\mathrm{x}: \mathrm{H}$ film (the latter having both interfaces grown $\mathrm{CO}_{2}$-free are compared, and each solar cell was measured firstly after screen-printing, then after the $\mathrm{SiO}_{\mathrm{x}}$ deposition, and finally after a 3-week forward-bias treatment. As can be seen, both processes lead to efficiency improvements. The $\mathrm{SiO}_{x}$ deposition improves mostly $\mathbf{J}_{\mathrm{SC}}$ as previously observed, as well as FF through series-resistance reduction. An unexpected but systematic $\mathrm{V}_{\mathrm{OC}}$ increase of a few $\mathrm{mV}$ is also observed, which could be due to further curing of the sputtering damage, modification of the work-function of the $\mathrm{IZrO}$ layer following hydrogenation, or interaction of hydrogen with the passivating (i)a-Si:H layer. Conversely, the forward bias treatment improves mostly $\mathrm{FF}$ through $\mathrm{FF}_{0}$ as well as $\mathrm{V}_{\mathrm{OC}}$, thus passivation, without altering $\mathrm{J}_{\mathrm{SC}}$. As in the previous section, the series resistance is higher when using a (p)nc-SiO $\mathrm{S}_{\mathrm{H}} \mathrm{H}$ compared to a (p)nc-Si:H film, leading to a slightly lower FF. There is, however, a smaller difference than in the previous experiment, suggesting that the non-thermally activated difference previously observed is indeed unrelated to the use of the (p)nc-SiO ${ }_{x}: H$ film. Overall, combining the (p)nc-SiO $: H$ hole contact with tailored interfaces, the $\mathrm{IZrO}$ layer, the $\mathrm{SiO}_{\mathrm{x}}$ coating, and the forward bias treatment enables a remarkable $24.1 \%$ efficiency. The best cell of this series was independently certified with the same efficiency value, as shown in Figure 6.

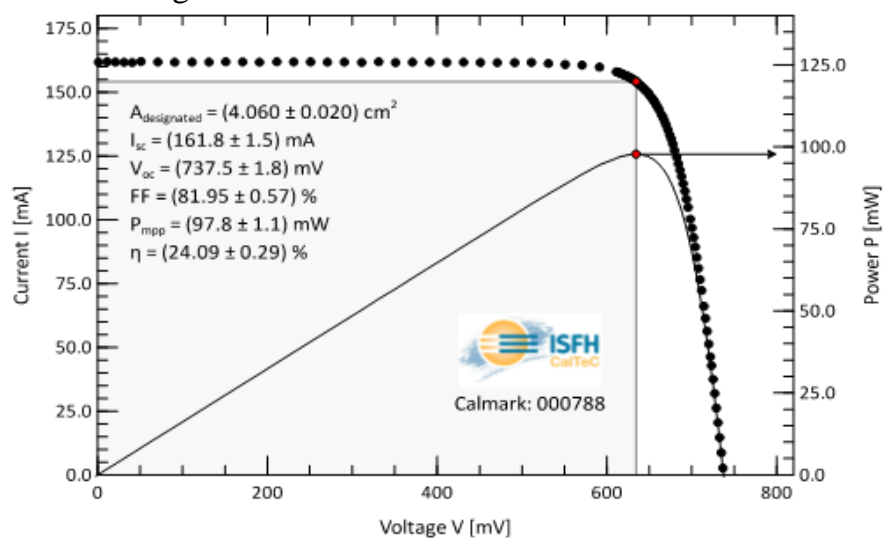

Fig. 6. Certified current-voltage characteristic of a silicon heterojunction solar cell incorporating the developments discussed above.

\section{OUTLOOK}

In a further batch of experiments, thinning down the (i)a$\mathrm{Si}: \mathrm{H}$ film as well as the oxide part of the (p)nc-SiO $\mathrm{x}: \mathrm{H}$ film (from three minutes and a half of deposition to two minutes) was shown beneficial. Indeed, similar electrical performances were maintained, with less than a millivolt of $\mathrm{V}_{\mathrm{OC}}$ drop and a 
This is the accepted version of the article "Hole-selective front contact stack enabling 24.1\%-efficient silicon heterojunction solar cells" from M. Boccard et al., DOI: 10.1109/JPHOTOV.2020.3028262

(C) (C) 2019 IEEE. Personal use of this material is permitted. Permission from IEEE must be obtained for all other uses, in any current or future media, including reprinting/republishing this material for advertising or promotional purposes, creating new collective works, for resale or redistribution to servers or lists, or reuse of any copyrighted component of this work in other works.

Publisher version available at https://ieeexplore.ieee.org/abstract/document/9223729

$0.1 \%$ abs FF improvement(pseudo-FF dropped by half a percent, which was compensated by a series resistance reduction of 0.1 $\Omega . \mathrm{cm}^{2}$ ). On the other hand, these two thickness reductions decreased parasitic blue-light absorption, as shown in Figure 7, amounting to $0.25 \mathrm{~mA} / \mathrm{cm}^{2} \mathrm{~J}_{\mathrm{SC}}$ gain each. This total $\mathrm{J}_{\mathrm{SC}}$ increase of $0.5 \mathrm{~mA} / \mathrm{cm}^{2}$ thus enabled a slight efficiency gain compared to the reference sample processed identically to the $24.1 \%$ certified device. Going beyond the window-layer, a similar $0.6 \mathrm{~mA} / \mathrm{cm}^{2} \mathrm{~J}_{\mathrm{SC}}$ gain on the infrared part of the spectrum is demonstrated in Figure 7, through the replacement of the thick ITO film by the combination a thin ITO layer with a partial $\mathrm{MgF}_{2}$ coating prior to the full-area silver layer [50]. The insertion of this low-refractive-index layer reduces plasmonic absorption in the rear silver metallization. However, low $\mathrm{V}_{\mathrm{OC}}$ and FF were measured for this device, presumably due to improper processing order of this advanced rear reflector. Yet, combining the two approaches gives a path towards further improvements to approach $25 \%$ efficiency for silicon heterojunction solar cells in the front-junction configuration using screen-printed contacts. Going further would likely require more advanced metallization such as copper plating or using photolithography, and the production of a higher volume of samples to acquire sufficient statistics for fine-tuning of each layer properties.

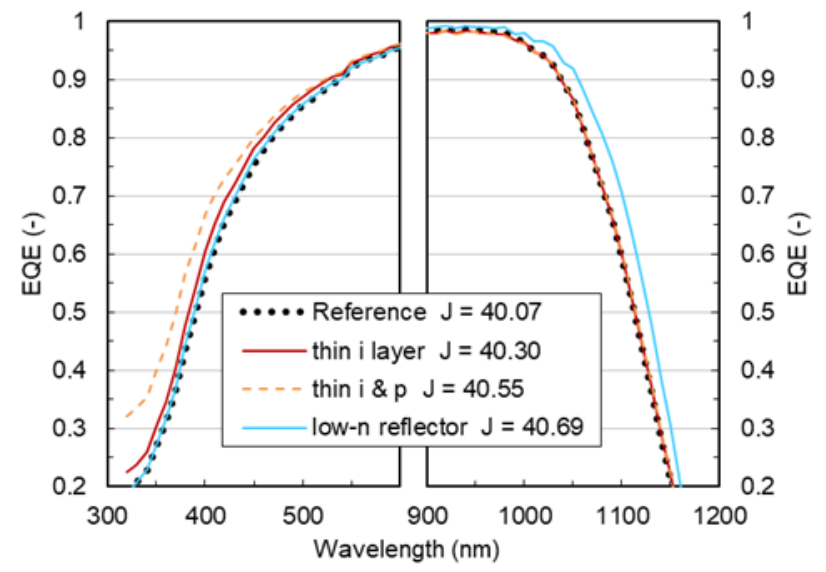

Fig. 7. $\mathrm{EQE}$ of solar cells with variations in the front-contact stack or rear reflector focusing on the short- and long-wavelength ranges.

Finally, although all the processes employed here rely on industry-relevant processes, several aspects would need attention towards their implementation in production environment. Firstly, concerning IZrO sputtering, an industrial tool with a $378 \times 120 \mathrm{~mm}^{2}$ linear target was used in this experiment. A slower scanning speed was used compared to our ITO standard recipe, and radio-frequency (RF) excitation was used in lieu direct-current (DC). Investigating the possibility to deposit with a higher throughput with DC excitation-which was not tested here-would therefore be required. Secondly, part of the optical benefits of the $\mathrm{SiO}_{x}$ capping would be lost in an encapsulated module: the surrounding medium of the TCO on the light-incoming side has in that case a refractive index close to 1.5. A similar strategy was however shown industry-relevant by using an $\mathrm{SiN}_{\mathrm{x}}$ layer, which is less costly than the ITO layer and yield a $0.2 \%$ efficiency increase in industrial laboratory from optical benefit [35]. The electrical gains might be maintained in that case (although no FF improvement is reported in [35] using ITO and industry-optimized a-Si:H layers), and excellent antireflective performances could be reached by capping a relatively thin $<50$-nm-thick IZrO film with an oxynitride layer $\left(\mathrm{SiN}_{\mathrm{x}} \mathrm{O}_{\mathrm{y}}\right)$ which can provide a transparent layer with an optimal refractive index of 1.7. Then, the (p)nc-SiO $\mathrm{S}_{\mathrm{x}} \mathrm{H}$ layer used in this study required four minutes of deposition, which is incompatible with cost-effective industrial throughput. Decreasing the deposition time-which again was not tackled in this study — would thus also be required. Finally, although minimal degradation was measured after a few weeks for unencapsulated devices presented here, more attention should be paid to the reliability of modules employing such layers.

\section{CONCLUSION}

We applied multiple alterations to the window-layer stack of front-junction silicon heterojunction solar cells to improve their performance. By combining a p-type mixed-phase nanocrystalline silicon oxide hole-collecting layer, a zirconium-doped indium oxide capped with silicon-oxide as an antireflective transparent conductive stack, and a forward bias treatment, we fabricated a silicon heterojunction solar cell with an independently confirmed $24.1 \%$ efficiency. The high transparency and conductivity of this stack enable simultaneous reaching of a current density close to $40 \mathrm{~mA} / \mathrm{cm}^{2}$ together with a FF close to $82 \%$ while using a single screenprinting metallization step. We could evidence that improvements could be combined together without detrimental interaction. We notably observed a beneficial reduction in series resistance when depositing an $\mathrm{SiO}_{x}$ layer on an $\mathrm{IZrO}$ film, and demonstrated that a forward electrical bias can boost performance of finished devices incorporating a (p)nc-SiO $\mathrm{x}: \mathrm{H}$ layer. Paths towards further improvements are discussed, notably through fine-tuning of the (i)a-Si:H and (p)nc-SiO $: H$ layers for further opto-electrical gains, or alteration of the rear electrode to reduce infrared-light parasitic absorption. The combination of both already evidenced a potential for over $1 \mathrm{~mA} / \mathrm{cm}^{2}$ of $\mathbf{J}_{\mathrm{SC}}$ improvement.

\section{ACKNOWLEDGMENT}

The authors thank Patrick Wyss, Christophe Allebé and Nicolas Badel from CSEM for the high-quality wet-processing 
This is the accepted version of the article "Hole-selective front contact stack enabling $24.1 \%$-efficient silicon heterojunction solar cells 8 from M. Boccard et al., DOI: 10.1109/JPHOTOV.2020.3028262

(C) (C) 2019 IEEE. Personal use of this material is permitted. Permission from IEEE must be obtained for all other uses, in any current or future media, including reprinting/republishing this material for advertising or promotional purposes, creating new collective works, for resale or redistribution to servers or lists, or reuse of any copyrighted component of this work in other works.

Publisher version available at https://ieeexplore.ieee.org/abstract/document/9223729

and metallization, as well as Aymeric Schafflützel and Cédric Bucher for their outstanding maintenance of PV-lab's equipment park.

\section{REFERENCES}

[1] D. S. Philipps and W. Warmuth, "Fraunhofer ISE: Photovoltaics Report, updated: 14 March 2019," Fraunhofer ISE Photovoltaics Report, Updat. 14 March 2019, no. March, 2019.

[2] M. A. Green, "The path to $25 \%$ silicon solar cell efficiency: History of silicon cell evolution," Prog. Photovoltaics Res. Appl., vol. 17, no. 3, pp. 183-189, May 2009.

[3] T. G. Allen, J. Bullock, X. Yang, A. Javey, and S. De Wolf, "Passivating contacts for crystalline silicon solar cells," Nat. Energy, Sep. 2019.

[4] K. Yamamoto, K. Yoshikawa, H. Uzu, and D. Adachi, "Highefficiency heterojunction crystalline Si solar cells," in Japanese Journal of Applied Physics, 2018.

[5] C. Hollemann, F. Haase, S. Schäfer, J. Krügener, R. Brendel, and R. Peibst, "26.1\%-efficient POLO-IBC cells: Quantification of electrical and optical loss mechanisms," Prog. Photovoltaics Res. Appl., vol. 27, no. 11, pp. 950-958, 2019.

[6] D. Adachi, J. L. Hernández, and K. Yamamoto, "Impact of carrier recombination on fill factor for large area heterojunction crystalline silicon solar cell with $25.1 \%$ efficiency," Appl. Phys. Lett., vol. 107, no. 23, p. 233506, Dec. 2015.

[7] X. Ru et al., " $25.11 \%$ Efficiency Silicon Heterojunction Solar Cell With Low Deposition Rate Intrinsic Amorphous Silicon Buffer Layers," Sol. Energy Mater. Sol. Cells, vol. 215, no. January, p. 110643, 2020.

[8] A. Richter, J. Benick, F. Feldmann, A. Fell, M. Hermle, and S. W. Glunz, "n-Type Si solar cells with passivating electron contact: Identifying sources for efficiency limitations by wafer thickness and resistivity variation," Sol. Energy Mater. Sol. Cells, vol. 173, pp. 96-105, Dec. 2017.

[9] Z. C. Holman et al., "Current losses at the front of silicon heterojunction solar cells," IEEE J. Photovoltaics, vol. 2, no. 1, pp. 7-15, 2012.

[10] A. Onno, C. Chen, P. Koswatta, M. Boccard, and Z. C. Holman, "Passivation, conductivity, and selectivity in solar cell contacts: Concepts and simulations based on a unified partial-resistances framework," J. Appl. Phys., vol. 126, no. 18, p. 183103, 2019.

[11] A. Descoeudres et al., "Advanced silicon thin films for highefficiency silicon heterojunction-based solar cells," in 2017 IEEE 44th Photovoltaic Specialist Conference (PVSC), 2017, pp. 50-55.

[12] H. Sai, P. W. Chen, H. J. Hsu, T. Matsui, S. Nunomura, and K. Matsubara, "Impact of intrinsic amorphous silicon bilayers in silicon heterojunction solar cells," J. Appl. Phys., vol. 124, no. 10, 2018.

[13] W. Liu et al., "Damp-Heat-Stable, High-Efficiency, Industrial-Size Silicon Heterojunction Solar Cells," Joule, pp. 1-15, 2020.

[14] T. Koida, H. Fujiwara, and M. Kondo, "High-mobility hydrogendoped $\mathrm{In} 2 \mathrm{O} 3$ transparent conductive oxide for a-Si:H/c-Si heterojunction solar cells," Sol. Energy Mater. Sol. Cells, vol. 93, no. 6-7, pp. 851-854, 2009.

[15] L. Barraud et al., "Hydrogen-doped indium oxide/indium tin oxide bilayers for high-efficiency silicon heterojunction solar cells," Sol. Energy Mater. Sol. Cells, vol. 115, pp. 151-156, 2013.

[16] E. Kobayashi, Y. Watabe, T. Yamamoto, and Y. Yamada, "Cerium oxide and hydrogen co-doped indium oxide films for highefficiency silicon heterojunction solar cells," Sol. Energy Mater. Sol. Cells, vol. 149, pp. 75-80, 2016.

[17] J. P. Seif et al., "Strategies for Doped Nanocrystalline Silicon Integration in Silicon Heterojunction Solar Cells," IEEE J. Photovoltaics, vol. 6, no. 5, 2016.
[18] L. Mazzarella, A. B. Morales-Vilches, L. Korte, R. Schlatmann, and B. Stannowski, "Ultra-thin nanocrystalline n-type silicon oxide front contact layers for rear-emitter silicon heterojunction solar cells," Sol. Energy Mater. Sol. Cells, 2018.

[19] C. Peng et al., "High Phosphorus-doped Seed Layer in Microcrystalline Silicon Oxide Front Contact Layers for Silicon Heterojunction Solar Cells," in 2019 IEEE 46th Photovoltaic Specialists Conference (PVSC), 2019, pp. 2550-2553.

[20] J. Haschke, C. Messmer, J. Cattin, M. Bivour, M. Boccard, and C. Ballif, "Injection-dependent lateral resistance in front-junction solar cells with nc-Si:H and a-Si:H hole selective contact," in Conference Record of the IEEE Photovoltaic Specialists Conference, 2019, pp. 3042-3045.

[21] Y. Zhao et al., "Doped hydrogenated nanocrystalline silicon oxide layers for high-efficiency c-Si heterojunction solar cells," Prog. Photovoltaics Res. Appl., vol. 28, no. 5, pp. 425-435, 2020.

[22] A. Richter, V. Smirnov, A. Lambertz, K. Nomoto, K. Welter, and K. Ding, "Versatility of doped nanocrystalline silicon oxide for applications in silicon thin-film and heterojunction solar cells," Sol. Energy Mater. Sol. Cells, vol. 174, no. July 2017, pp. 196-201, 2018.

[23] P. Sichanugrist, T. Yoshida, Y. Ichikawa, and H. Sakai, "Amorphous silicon oxide with microcrystalline Si phase," J. Non. Cryst. Solids, vol. 164-166, P, no. 0, pp. 1081-1084, 1993.

[24] P. Cuony et al., "Mixed-phase p-type silicon oxide containing silicon nanocrystals and its role in thin-film silicon solar cells," Appl. Phys. Lett., vol. 97, no. 21, p. 213502, 2010.

[25] R. Biron, C. Pahud, F. J. Haug, J. Escarré, K. Söderström, and C. Ballif, "Window layer with $\mathrm{p}$ doped silicon oxide for high $\mathrm{V}$ oc thin-film silicon n-i-p solar cells," J. Appl. Phys., vol. 110, no. 12, p. 124511 , Dec. 2011.

[26] H. Sai, T. Matsui, H. Kumagai, and K. Matsubara, "Thin-film microcrystalline silicon solar cells: $11.9 \%$ efficiency and beyond," Appl. Phys. Express, vol. 11, no. 2, pp. 8-12, 2018.

[27] L. Mazzarella, S. Kirner, B. Stannowski, L. Korte, B. Rech, and R. Schlatmann, "P-type microcrystalline silicon oxide emitter for silicon heterojunction solar cells allowing current densities above 40 mA/cm2," Appl. Phys. Lett., vol. 106, no. 2, pp. 0-5, 2015.

[28] M. Morales-Masis et al., "Highly Conductive and Broadband Transparent Zr-Doped In2O3 as Front Electrode for Solar Cells," IEEE J. photovoltaics, vol. 8, no. 99, pp. 1202-1207, 2018.

[29] T. Koida, H. Fujiwara, and M. Kondo, "High-mobility hydrogendoped In 2 O3 transparent conductive oxide for a-Si:H/c-Si heterojunction solar cells," Sol. Energy Mater. Sol. Cells, vol. 93, no. 6-7, pp. 851-854, 2009.

[30] J. Yu et al., "Tungsten doped indium oxide film: Ready for bifacial copper metallization of silicon heterojunction solar cell," Sol. Energy Mater. Sol. Cells, vol. 144, pp. 359-363, 2015.

[31] T. Koida, Y. Ueno, and H. Shibata, "In 2 O 3 -Based Transparent Conducting Oxide Films with High Electron Mobility Fabricated at Low Process Temperatures," Phys. status solidi, vol. 215, no. 7, p. 1700506, Apr. 2018.

[32] M. Boccard, N. Rodkey, and Z. C. Holman, "High-mobility Hydrogenated Indium Oxide without Introducing Water During Sputtering," Energy Procedia, vol. 92, pp. 297-303, Aug. 2016.

[33] S. Y. Herasimenka, W. J. Dauksher, M. Boccard, and S. Bowden, "ITO/SiOx:H stacks for silicon heterojunction solar cells," Sol. Energy Mater. Sol. Cells, vol. 158, pp. 98-101, 2016.

[34] A. B. Morales-Vilches et al., "ITO-Free Silicon Heterojunction Solar Cells With $\mathrm{ZnO}: \mathrm{Al} / \mathrm{SiO} 2$ Front Electrodes Reaching a Conversion Efficiency of 23\%," IEEE J. Photovoltaics, vol. 9, no. 1, pp. 34-39, 2019.

[35] D. L. Bätzner et al., "Alleviating performance and cost constraints in silicon heterojunction cells with HJT 2.0," in 2019 IEEE 46th Photovoltaic Specialists Conference (PVSC), 2019, pp. 14711474 . 
This is the accepted version of the article "Hole-selective front contact stack enabling 24.1\%-efficient silicon heterojunction solar cells9 from M. Boccard et al., DOI: 10.1109/JPHOTOV.2020.3028262

(C) (C) 2019 IEEE. Personal use of this material is permitted. Permission from IEEE must be obtained for all other uses, in any current or future media, including reprinting/republishing this material for advertising or promotional purposes, creating new collective works, for resale or redistribution to servers or lists, or reuse of any copyrighted component of this work in other works.

Publisher version available at https://ieeexplore.ieee.org/abstract/document/9223729

[36] E. Kobayashi et al., "Light-induced performance increase of silicon heterojunction solar cells," Appl. Phys. Lett., vol. 109, no. 15, pp. 1-6, 2016.

[37] E. Kobayashi et al., "Increasing the efficiency of silicon heterojunction solar cells and modules by light soaking," Sol. Energy Mater. Sol. Cells, no. March, pp. 0-1, 2017.

[38] L. Mazzarella et al., "Nanocrystalline silicon emitter optimization for Si-HJ solar cells: Substrate selectivity and CO2 plasma treatment effect," Phys. Status Solidi Appl. Mater. Sci., 2017.

[39] M. Boccard, R. Monnard, L. Antognini, and C. Ballif, "Silicon oxide treatment to promote crystallinity of p-type microcrystalline layers for silicon heterojunction solar cells," in AIP Conference Proceedings, 2018, vol. 1999, no. 1, p. 40003.

[40] A. Cruz et al., "Influence of Silicon Layers on the Growth of ITO and AZO in Silicon Heterojunction Solar Cells," IEEE J. Photovoltaics, vol. 10, no. 2, pp. 703-709, 2020.

[41] A. Cruz et al., "Effect of front TCO on the performance of rearjunction silicon heterojunction solar cells: Insights from simulations and experiments," Sol. Energy Mater. Sol. Cells, 2019.

[42] P. Mahtani, R. Varache, B. Jovet, C. Longeaud, J.-P. Kleider, and N. P. Kherani, "Light induced changes in the amorphouscrystalline silicon heterointerface," J. Appl. Phys., vol. 114, no. 12, p. 124503, Sep. 2013.

[43] J. Cattin, M. Boccard, and C. Ballif, "Passivation and Transport Modification Upon Light Soaking of Silicon Heterojunction Solar Cells," 2020.

[44] A. N. Fioretti, M. Boccard, R. Monnard, and C. Ballif, "LowTemperature p-Type Microcrystalline Silicon as Carrier Selective Contact for Silicon Heterojunction Solar Cells," IEEE J.

Photovoltaics, vol. 9, no. 5, pp. 1158-1165, 2019.

[45] Z. C. Holman et al., "Infrared light management in high-efficiency silicon heterojunction and rear-passivated solar cells," J. Appl. Phys., vol. 113, no. 1, p. 013107, 2013.

[46] J. Haschke et al., "Annealing of Silicon Heterojunction Solar Cells: Interplay of Solar Cell and Indium Tin Oxide Properties," IEEE J. Photovoltaics, vol. 9, no. 5, pp. 1202-1207, Sep. 2019.

[47] L. Mazzarella et al., "Nanocrystalline Silicon Oxide Emitters for Silicon Hetero Junction Solar Cells," Energy Procedia, vol. 77, pp. 304-310, Aug. 2015.

[48] P. Procel, G. Yang, O. Isabella, and M. Zeman, "Theoretical evaluation of contact stack for high efficiency IBC-SHJ solar cells," Sol. Energy Mater. Sol. Cells, vol. 186, no. May, pp. 66-77, 2018.

[49] M. Taguchi, E. Maruyama, and M. Tanaka, "Temperature Dependence of Amorphous/Crystalline Silicon Heterojunction Solar Cells," Jpn. J. Appl. Phys., vol. 47, no. 2, pp. 814-818, Feb. 2008.

[50] Z. C. Holman, A. Descoeudres, S. De Wolf, and C. Ballif, "Record infrared internal quantum efficiency in silicon heterojunction solar cells with dielectric/metal rear reflectors," IEEE J. Photovoltaics, vol. 3, no. 4, pp. 1243-1249, 2013. 